\title{
Bogotá desde el rap bogotano: sin amigos, sin ley y sin futuro ${ }^{2}$
}

\author{
Bogotá City from Bogotanian Rap: \\ without Friends, without Law and without Future
}

\begin{abstract}
Resumen
El presente artículo realiza un análisis de la manera en la que se representa a la ciudad de Bogotá en las canciones del rap bogotano contemporáneo. Este ejercicio es uno de los resultados de la investigación de Maestría: "Microphone Guerrillo. Un estudio de las representaciones sociales sobre identidad en las líricas del rap bogotano". En el estudio se trabajó con un corpus documental consistente en 54 canciones de rap, que forman parte de los siguientes álbumes discográficos: "Por siempre" (La Etnnia, 2008); "La ciencia de los sueños" (JHT, 2009); “Nací Mujer" (Diana Avella, 2010); "Mix tape" (Tres Coronas, 2006); "7 pecados capitales" (Juan Habitual, 2007) y "Sucio Sur" (Fondo Blanco, 2009).
\end{abstract}

Palabras clave: rap bogotano, representaciones sociales.

\begin{abstract}
This article presents an analysis on how Bogotá city is represented in contemporary bogotanian rap songs. This paper is part of the results of a research project entitled: "Microphone Guerrillo. A study of social representations of identity in the lyrics of bogotanian rap". In the study was selected a corpus of 54 rap songs which belong to the following discography albums: "Por siempre" (La Etnnia, 2008); "La ciencia de los sueños" (JHT, 2009); "Naci Mujer" (Diana Avella, 2010); "Mix tape" (Tres Coronas, 2006); "7 pecados capitales" (Juan Habitual, 2007) y "Sucio Sur" (Fondo Blanco, 2009).
\end{abstract}

Keywords: bogotanian rap, social representations

Recibido el 23 de octubre de 2013 y aprobado el 4 de noviembre de 2013

1 Sociólogo de la Universidad Nacional de Colombia. Magíster en Investigación Social Interdisciplinaria de la Universidad Distrital Francisco José de Caldas. Coordinador del Observatorio de Procesos de Organización Comunitaria. Correo electrónico: sociologiaumd@gmail.com

2 Artículo resultado de la investigación "Microphone Guerrillo. Un estudio de las representaciones sociales sobre identidad en las líricas del rap bogotano". 
"La música como organización más abstracta del tiempo es capaz de connotar la singularidad expresiva de un momento, en tanto proceso de apropiación subjetiva, como de revelar los significados compartidos en torno a información relacional que denota el espacio musical ocupado por esa comunidad dentro del devenir bistórico"

García (2006)

"Solamente se percibe un gran olor, olor a desconfianza, como cuando el reo paga su fianza, porque detrás de la cortina alguien te caza, sólo mirar y caminar con ojos de vigilancia. Andenes inquietos, callejones con manes adheridos, con puñales desafiándote a un reto; bienvenido a la ciudad de la sospecha, yo soy sobreviviente en ella basta la fecha”

Canción: "La ciudad de la sospecha". Grupo: La Etnnia

\section{Introducción}

Algunos temas han permeado la discursividad de casi todas las músicas populares contemporáneas: el amor, el placer, la experimentación, la política, las reminiscencias de lo folclórico y la ciudad como universo de paisajes, representaciones, lugares, relaciones, prácticas, actores, usos del lenguaje, caminos, memorias y sueños. Oír música es escuchar la voz de las ciudades en las canciones, en donde el mundo urbano se hace sonido y palabra, reflejando múltiples territorios imaginados.
Una ciudad como Nueva York, por poner un ejemplo, existe de manera distinta en la voz de Frank Sinatra (New York, New York), en la del Gran Combo de Puerto Rico (Un verano en Nueva york), y en la de Sting (Englishman in New york). La potencia de lo musical para masificar representaciones hace de las canciones sobre la ciudad un artefacto cultural poderoso para objetivar y anclar diferentes maneras de imaginar el mundo urbano, las cuales tienen incidencia en las múltiples relaciones que los sujetos construyen con la ciudad.

En este artículo se presenta un recorrido por la ciudad representada en el rap bogotano, tratando de situar los matices con los que estos artistas proponen una construcción simbólica particular de Bogotá. Este es uno de los resultados de la Investigación: "Microphone Guerrillo. Un estudio de las representaciones sociales sobre identidad en las líricas del rap bogotano", con la cual opté por el título de Magíster en investigación social interdisciplinaria, en la Universidad Francisco José de Caldas, en el Año 2012. En el trabajo se aborda la manera en la que los raperos bogotanos se representan a sí mismos, al sector de la población al que pertenecen y al espacio urbano que los contiene, a partir de las letras de las canciones de los álbumes más representativos del género, producidos en los últimos cinco años. A saber: "Por siempre" (La Etnnia, 2008); "La ciencia de los sueños" (JHT, 2009); "Nací mujer" (Diana Avella, 2010); "Mix tape" (Tres Coronas, 2006); “7 pecados capitales” (Juan Habitual, 2007) y "Sucio sur" (Fondo Blanco, 2009).

Nuestra labor en este artículo será llevar a cabo un énfasis especial en la ciudad, como marco de todas las interacciones, relaciones y significados. A lo largo del artículo trataremos de dar la voz a los cantantes, citando las canciones que se analizaron en el estudio, con el fin de que el lector pueda ir haciendo su propia interpretación de los textos del rap.

\section{Algunas precisiones teóricas}

Acercarnos al tema de la producción, circulación y consumo musical, y a los sentidos que 
en estos procesos se construyen y reconstruyen, implica definir unas coordenadas epistemológicas claras. Para ello es necesario plantearse algunas preguntas iniciales: ¿Cómo construir conocimiento alrededor de lo musical? ¿Dónde situarse para entender el sentido de las canciones? ¿Desde el poder creativo de los sujetos o desde las fuerzas que determinan su creación? ¿La música crea, refleja, refracta, imita, propone, interpreta o interpela la vida social?

La producción musical de los raperos se mueve en varias tensiones que vale la pena presentar para ampliar algunos de los matices en la construcción de nuestro objeto de estudio. La primera tensión se ubica entre lo global y lo local. En un momento de transnacionalización en la producción de las representaciones sociales, la música es uno de los ejemplos emblemáticos del trayecto de lo simbólico entre lo global y lo local. El rap bogotano no puede ser entendido sólo desde la transnacionalización inherente a la cultura hip hop, pero tampoco se agota en la atenta observación e interpretación de lo local. El surgimiento de la cultura H.H. en Harlem (New york), y los procesos de difusión, reelaboración, historización y mediatización, que ésta ha tenido desde entonces, son necesarios para la historicidad necesaria en el análisis del fenómeno. Pero el reconocimiento de las dinámicas particulares al contexto local, desde lo material y lo simbólico, son necesarias para la contextualidad de los análisis que presentamos.

La siguiente tensión se ubica entre lo mediático y lo barrial. El rap es una música que tiene una presencia dentro de las agendas de los medios de comunicación. En la actualidad, esta música, a nivel nacional y distrital, no cuenta con una difusión amplia. En el dial no hay una emisora especializada y sólo dos estaciones pasan, ocasionalmente, canciones de rap en horarios que no son precisamente los más estelares. En la televisión, el género tampoco circula asiduamente (sólo existe un programa de televisión de rap, más adelante precisaremos al respecto), lo cual ubica a Internet como el canal más importante de difusión que encuentran los artistas de este género. Éste no es ajeno a lo mediático, está construido desde sus lógicas, ha viajado por el mundo gracias a sus posibilidades; sin embargo, su producción sigue tendiendo a lo underground.

De otro lado, en las esquinas del barrio Tintal, del Codito, del Paraíso, de las Cruces, los jóvenes se reúnen a improvisar cotidianamente. Las pistas se cargan en reproductores portátiles y estallan en speakers que sirven de instrumentación a las rimas de los M.C. ${ }^{3}$ En un contexto donde la música está cada vez más sobreproducida e involucra elementos técnicos y tecnológicos cada vez más sorprendentes, el rap sigue teniendo la espontaneidad de la improvisación y de la calle.

Otra tensión importante se ubica entre lo institucional y lo proscrito de su producción. En los discursos de los M.C. aparece una posición de rechazo frente al mundo institucional. La visión distópica, rebelde y "contrahegemónica" parece chocar con la militancia en organizaciones sociales, en eventos, proyectos y programas estatales. Si bien el discurso es claramente contestatario, es precisamente la administración pública quien ha abierto buena parte de los espacios, locales y distritales, en los que circulan los M.C. a pesar de que en las líricas se refleja una posición anómica y de descreimiento, los jóvenes vinculados a esta cultura urbana terminan por generar procesos de organización y participación social y política. Grupos como Contrapeso y Revolución Artística Popular, que operan en la localidad de Ciudad Bolívar, los cuales conocí a través de pesquizas en Internet, y de mi asistencia a conciertos organizados por ellos, proponen acciones conjuntas y procesos colectivos al interior de los jóvenes. Carlos Mario Perea (2008) en su texto Somos expresión, no subversión reseña algunos de estos procesos. Esta tensión no implica una paradoja, o una contradicción, es simplemente una muestra de cómo opera lo

3 Este es el apelativo que reciben los cantantes de rap al interior del género. 
instituido y lo instituyente al interior de estas culturas juveniles.

Cualquier estudio sobre las músicas populares debe considerar atentamente la riqueza semántica de los discursos y prácticas sociales que en ellas convergen. La música —a pesar de ser un universo en sí mismo- aparece ante nosotros como una ventana hacia los significados que los públicos, los mediadores y los artistas crean y recrean. La producción y el consumo musical son procesos cargados de sentido y con implicaciones tanto en lo material como en lo simbólico, especialmente en el mundo de lo joven.

De ahí que las preguntas que hoy nos hacemos frente a la juventud pasan frecuentemente por los consumos culturales y en particular por el consumo de obras musicales. Como señala De Garay: "La música se constituye así en un complejo entramado de sentidos; opera en las prácticas culturales de los jóvenes como elemento socializador y al mismo tiempo como diferenciador de estatus o de papel" (2004, p. 1). Música y juventud se entrecruzan de distintas maneras en la trama de nuestras sociedades contemporáneas, en donde la circulación de materiales simbólicos se caracteriza por una velocidad que deviene en la saturación y posibilidad de las mixturas.

De otro lado, hablar de la juventud, de una manera indeterminada, puede resultar impreciso y naturalizante, puesto que: "La juventud es un concepto hibrido, en movimiento y en reconfiguración permanente, pues se trata de un concepto vacío de contenido, en tanto no se precise su contexto histórico y sociocultural" (Garcés, 2008, p. 1). Por ello, hablaremos entonces de una cultura juvenil urbana específica: el hip hop; situada en un contexto espacio temporal determinado: la Bogotá contemporánea, y representada en unas obras musicales (álbumes de rap) que han adquirido un cierto reconocimiento dentro de la escena local.

En relación a la categoría de representaciones sociales, Jean Claude Abric ha planteado el análisis de las estructuras representacionales de la siguiente manera: "Si los métodos clásicos de recolección de las representaciones pueden permitir entrar a la estructura interna de la representación, es generalmente a partir del análisis en profundidad de las producciones discursivas" (2001, p. 64). Convenimos con Abric en la posibilidad de comprender el mundo de lo representacional a partir de las producciones discursivas, razón por la que quiero subrayar una relación que resulta obvia en la realidad, pero que subyace al planteamiento que aquí desarrollaremos. Se trata de la relación entre el discurso de la música y las representaciones sociales que tanto oyentes como productores tienen frente a diferentes objetos y aspectos de la vida social. Esta relación es empíricamente observable, ya que lo dicho por los artistas, que son figuras visibles al interior de culturas juveniles, se relaciona con los discursos de los oyentes de los cuales son parte. Las representaciones plasmadas en la música popular tienen un asidero fuerte en el universo representacional del contexto que enmarca la emergencia de dicha música. Con esto no pretendemos señalar que la música, o mejor, el discurso musical, crea mecánicamente los otros discursos, sino que éste, al tener una posición visible y masiva, recoge y presenta unos significados que tienen una cierta legitimidad en los oyentes, quienes en el caso del rap reconocen a sus M.C. por la calidad y contenido de sus letras.

¿Cómo relacionar lo dicho hasta esta parte con las Representaciones Sociales? Partamos de las definiciones de Jodelet y Abric:

El concepto de representación social designa una forma de conocimiento específico, el saber del sentido común, cuyos contenidos manifiestan la operación de procesos generativos y funcionales socialmente caracterizados. En sentido más amplio, designa una forma de pensamiento social [...] La caracterización social de los contenidos o de los procesos de representación ha de referirse a las condiciones y a los contextos en los que surgen las representaciones, a las comunicaciones mediante las que circulan y a las funciones a las que sirven dentro de la interacción con el mundo y los demás (Jodelet, 1988, p. 474). 
Por su parte, Abric señala:

La representación funciona como un sistema de interpretación de la realidad que rige las relaciones de los individuos con su entorno físico o social, ya que determinará sus comportamientos o sus prácticas. Es una guía para la acción, orienta las acciones y relaciones sociales. Es un sistema de pre-decodificación de la realidad puesto que determina un conjunto de anticipaciones y expectativas (2001, p. 13).

Las representaciones funcionan, entre otras cosas, para interpretar la realidad, para moverse y relacionarse en ella. Así mismo, en cuanto que cantera de sentido, se ponen en juego cuando los agentes elaboran sus producciones discursivas, cuando componen música y posicionan un mensaje al interior de un grupo social. Los individuos comparten representaciones sociales, visiones, posiciones e informaciones sobre la realidad, o más claramente, sobre objetos, sujetos y categorías sociales.

[...] toda representación social es representación de algo y de alguien. Así, no es el duplicado de lo real, ni el duplicado de lo ideal, ni la parte subjetiva del objeto, ni la parte objetiva del sujeto. Sino que constituye el proceso por el cual se establece su relación (Jodelet, 1998, p. 476).

Los discursos de la música circulan a gran velocidad cruzando fronteras y agrupando personas alrededor de ciertos significados sociales y en su viaje continuo van siendo apropiados y resignificados por los oyentes, quienes los leen desde unos sistemas de interpretación que completan la canción, la incorporan y la dotan de significado tanto para el agente como para el grupo.

\section{La ciudad es musa}

El rap llega a Bogotá hacia mediados de los años ochenta gracias a películas como Breakdance o Beatstreet. Los jóvenes de clase media alta de la localidad de Suba serán los primeros en acoger esta música, la cual pasará a finales de la década a ser central en la actividad cultural de los "parches" del centro y sur de la ciudad, en particular, en las localidades Santa Fe y Ciudad Bolívar. ${ }^{4}$ En Bogotá aparecen dos bandas que son consideradas por la crítica como las pioneras del género en Latinoamérica: Gotas de Rap y la Etnnia, exponentes del gansta rap, una música caracterizada por la denuncia política y las historias sicariales del gueto, representación transaccional del campo urbano popular.

El rap, con su rápida difusión en el sur, se convierte ahora en el trasfondo expresivo y político (en cuanto el contenido de sus canciones) del baile, y el gueto en el artefacto de sentido que articula los recuerdos alrededor de la marginalidad como eje de su narrativa (García, 2006, p. 141).

A lo largo de los noventa y de la primera década del siglo XXI, los raperos en Bogotá —en particular en la zona de la localidad de Ciudad Bolívar y en la zona de las Cruces, territorios de donde han emergido los artistas más representativos del género- han construido unos espacios de producción y circulación de su música, ligados, entre otras cosas, a las políticas culturales de las administraciones locales. Escenarios como Rap al Parque, por ejemplo, son muestra de ello; un festival al aire libre, financiado por la alcaldía, que convoca más de 50.000 jóvenes

4 "[...] de todas las localidades, es quizás Ciudad Bolívar la que mejor represente el estigma que se cierne en torno a la marginalidad, miseria y violencia del sur en Bogotá. Su nombre evoca automáticamente todos los males que puede sufrir un espacio suburbano en una gran metrópoli: los mayores grados de hacinamiento por presión demográfica, inmigración masiva de campesinos, altos índices de violencia, milicias guerrilleras y paramilitares en los barrios más altos, falta de servicios públicos, altas tasas de desempleo e informalización del trabajo y decenas de pandillas juveniles [...] El hip hop se ha nutrido de esta estigmatización y su crecimiento vertiginoso desde finales de los noventa lo debe a estas representaciones, decenas de grupos de Break dance y centenares de rap se pueden hallar en los mas de doscientos barrios de Ciudad Bolívar [...] y son ellos el arquetipo del ñero para la mayoría de los bogotanos; sólo basta ser adolescente y vivir allí para convertirse automáticamente en él" (García, 2006, p. 124). 
cada año, en el que la denuncia al Estado está a la orden del día.

La Bogotá de los bajos fondos ha sido un personaje exitoso en las producciones artísticas contemporáneas. Películas como "La Sangre y la lluvia", "Satanás", "La sociedad del semáforo", entre otras, han logrado un reconocimiento masivo, y con él, el posicionamiento de una forma de ver y representar la ciudad. De la misma manera, novelas como "Buda blues" o "35 muertos" han contribuido a consolidar una oferta cultural donde la ciudad del crimen es la protagonista. Este fenómeno de espectacularización del espacio urbano, y en particular de lo liminal, forma parte una diversa gama de producciones que encuentran correlatos en diferentes partes del globo (Piénsese en la música grupera en México o en las películas sobre la MS13, entre otras manifestaciones artísticas). Lo liminal es inspirador; lo liminal es atractivo y funciona como materia prima para fabricar épicas televisivas, cinematográficas, musicales y literarias.

En este contexto debemos entender el rap bogotano, evitando caer, sin embargo, en dos posibles trampas: 1) Concluir que lo dicho por el rap es una farsa mediática. 2) Olvidar que lo dicho por el rap se debe también a la lógica de un campo (Bourdieu) en donde unos agentes específicos, orientados por una Illusio, buscan posicionar unos bienes culturales que tienen condiciones materiales, simbólicas y sociales. La calle es el telón de fondo del rap. Todo sucede allí, ella contiene todos los personajes que parecen transitar sin rumbo por su fría espalda, lo que deviene en que otros lugares sociales como la escuela, la fábrica y el hogar no aparezcan en las tablas del género de manera tan recurrente.

Esto ya nos enfoca y nos acerca a la cuestión sobre cuál es la ciudad de la que se habla en estas canciones: la ciudad, hecha calle, es la musa, es el enemigo, pero también es el tablero en el que se juega la vida. En ella, los sobrevivientes, los M.C., escriben elegías a la sospecha y al frío.

En nuestro corpus identificamos tres núcleos centrales que organizan las representaciones de ciudad: la ciudad escenario, la ciudad escuela y la ciudad monstruo de mil cabezas. La ciudad es escenario en cuanto las prácticas de los M.C. (y en general la de los sujetos que transitan por el hip hop: bailarines, grafiteros, d.j.s.) suceden en el espacio urbano. Los ensayos, los toques y las rumbas, como prácticas que sostienen la cultura juvenil, en buena medida suceden en la calle. No existen en la ciudad muchos bares de rap y los rutinarios trayectos callejeros de los raperos hacen de la acera misma una tarima en donde se actúa, se canta, se escribe y se produce arte. Así lo presenta la canción mi barrio, de los cantantes Flaco Flow y Melanina:

"Caminando por las calles de mi barrio, saludando a la gente que veo a diario, el pueblo mi causa la calle es mi escenario, eh mi barrio".

El rock y sus estrellas han optado por los estadios y los club, lo mismo que muchas de las estrellas pop; mientras los raperos nadan en el asfalto. Es fácil ver a algunos de los M.C. reconocidos de la ciudad cantando en el septimazo o en eventos organizados por colectivos de raperos o por la administración distrital. La facilidad técnica de hacer shows, dado que no se requiere de un backline costoso y aparatoso, facilita el uso de la ciudad como tarima. El M.C camina y canta, y escribe sus rimas en un bus.

De otro lado aparece la ciudad escuela. El capital más escaso y valioso en el rap es la experiencia, la cual sólo es legítima si se logra en la ciudad. La calle es maestra, y en ella, los viandantes son guerreros y sobrevivientes de un espacio sin ley ni justicia. El rap es anómico por convicción. No existe orden en la ciudad fría, en la ciudad de la sospecha. Sin embargo, tampoco hay salida, ni propuesta; esto lo abordaremos más adelante. Mientras tanto, la gente del barrio continúa aprendiendo a vivir en una ciudad que no espera a los desesperados:

"Ey, barrio, guerreros legendarios luchando a diario tras un salario el cual no alcanza ni pal diario, muchos barrios pasan los calendarios y eso no es precario, sube todo menos el salario" (Flaco Flow \& Melanina, Mi barrio). 
Lo único que queda en la excluyente ciudad es aprender a sobrevivir aún en ausencia de destino:

"Es de frialdad construida esta ciudad. Cuanto más quien quiera su destino cambiar, habrá que luchar, afinar la voluntad, prepararse y olvidar que no hay marcha atrás” (Diana Avella, Vida).

La ciudad del rapero es la ciudad de la noche, el lado oscuro del espacio urbano en el que sólo existen los fantasmas:

"Sólo sombras quedan de una noche fría, caminando al compás de una sinfonía de grillos, a esa hora sólo parchan pillos, como en el oeste con el dedo en el gatillo" (La Etnnia, Nocturno).

Por último, aparece la ciudad monstruo de mil cabezas, en donde no es posible tener claro hacia donde va la vida y en donde nadie vela por la seguridad de nadie. Esta representación se relaciona con la manera en la que todos imaginamos Bogotá: una selva de cemento en donde el vínculo social es débil y los sujetos deben, por sí solos, encontrar el camino para seguir adelante:

Sigue pasando el tiempo en la ciudad fría. Nadie sabe donde va la vida. Entre suspiros, miedos y desdichas. No, no, no, no, no. Sigue luchando por encontrar la salida. Nadie sabe donde va la vida. Entre suspiros, miedos y desdichas (Diana Avella, Ciudad Fría).

La desconfianza es el olor de la ciudad: "En donde todos andan como un gallo fino a la defensiva, rodeados de killers, multitudes intranquilas" (La Etnnia, La ciudad de la sospecha). Algo particular de la ciudad imaginada en el rap es que en buena medida el enemigo no tiene rostro. Se habla de los maleantes, de los políticos, de un peligro sin forma que habita en los amigos, en el aire, pero que no es nombrado en cuanto es multiforme y omnipresente:

"Cuida tu equipaje en la ciudad salvaje, ciudad insegura croni crónica pura, ciudad de la sospecha donde el mal ejemplo acecha, sospecha, donde el crimen siempre acecha, parado en la ciudad de los temores" (La Etnnia, La ciudad de la sospecha).
La omnipresencia del mal, del crimen, del frío, de la sospecha, hacen que la representación del espacio urbano choque con la aparente seguridad que se propone desde algunos aparatos ideológicos del Estado. Ahora bien, esa ciudad inclemente que amenaza por todos los flancos y deja sin salida y sin propuestas al rap que habla de familia, de parche, pero también de la imposibilidad de confiar en el otro.

\section{El gueto en distintos colores}

La categoría del gueto viene desde la antigüedad, pasando por el Medioevo, hasta llegar a la Modernidad, en donde se identificó con el barrio judío de las ciudades de Europa. Después de la Segunda Guerra Mundial éste representa la segregación, voluntaria o involuntaria. Sin embargo, la historia del término ha adquirido muchas formas a lo largo de los siglos XX y XXI. En particular en el rap se ha adoptado como la forma de designar el espacio popular urbano. El gueto - en nuestra música- es una categoría transnacional, mediatizada a través de la música, los grafitis, los documentales, videos y películas. Lo interesante es que si bien es una categoría para designar lo territorial, funciona más allá de lo local y puede tener distintos sentidos y funcionar para nombrar diferentes escenarios al interior de la discursividad del rap.

El gueto es el barrio del M.C., pero es también otros barrios con condiciones de exclusión y desigualdad estructural. El gueto está en la cárcel, en las correccionales, en el ICBF, en la televisión, en las imágenes mediatizadas de la mara Salva Trucha y del barrio La Perla en Puerto Rico. Cejaz Negraz, líder de la agrupación Fondo Blanco, en una de sus canciones como solista, canta lo siguiente:

Yo represento toda la people en los guetos, en las prisiones, en los corregimientos, los internados donde el corazón sagrado acaricia los niños y no como el viento [...] los enfermos en los hospitales, a esos chingas perdidos en la calle [...] represento el barrio donde las ratas los rompen en el norte 
[...] los latinos en mis conciertos, la mara, netas king... yo represento la olla y los que habitan en ella (Gueto, Fondo Blanco, 2011).

No puede ser más ilustrativo el fragmento de la canción que acabamos de citar. El gueto, de lo local a lo global, se convierte en una imagen multiforme para representar la marginalidad, la desigualdad, la pobreza, la ilegalidad y la resistencia. Por ello, al interior del género la competencia se abre para poder retratar el gueto de la manera más "real". Al ser el gueto un tipo ideal del barrio, en sentido weberiano, los M.C. terminan reproduciendo unas homologías que si bien no están construidas sin fundamento, obedecen a una ficción estándar y multinacional de los sectores populares. En el gueto sólo hay noche, sólo habitan pillos y madres cabezas de familia, desplazados y desempleados, lo cual omite otros sujetos que también habitan el barrio y tienen actuaciones distintas a las que aparecen en las canciones. Sería interesante oír a los M.C hablando de los procesos comunitarios, de los jóvenes estudiantes que sacan adelante sus carreras, y de los microempresarios, entre otros personajes barriales, quizás menos espectaculares, pero también reales. Con esto no busco minimizar la expresión legítima de estos artistas, la cual respeto profundamente, pero quisiera evidenciar que en la discursividad del rap operan categorías representacionales y dispositivos de control al interior del campo, que hacen que los textos que allí se proponen vengan predeterminados y se constituyan como relatos de un barrio imaginado transnacionalmente, a partir de la experiencia en lo liminal de la ciudad. De esta forma, el gueto aparece como una representación fragmentada y unilateral de la sociedad del barrio.

Mas allá del rap, resulta interesante ver cómo - a la manera del hecho social de Durkheim ${ }^{5}$ en las formas de pensar y sentir la ciudad en la música operan moldes culturales que se reproducen gracias a las demandas del campo musical que predetermina unos temas y enfoques para abordarlos. Un escucha desprevenido sentirá una cierta homogeneidad al interior de los textos del rap. Ésta, sin duda, se debe a la frontera semiótica en donde se define qué es y qué no es considerable como rap, la cual es muy marcada, a contramano de un mundo que cada vez es más proclive a la fusión y a la ruptura de diferentes elementos estéticos y discursivos. Tal es la manera de operar del género como construcción no sólo estética sino también ideológica.

Lo que debe ser el gueto no admite discusión; y si bien, en la realidad de a puño los raperos viven en el barrio, con todas las discontinuidades, mezclas y contradicciones que eso implica, sus canciones parecieran habitar en la espectacular categoría del gueto que homogeniza el barrio latino en Harlem, con el barrio Paraíso de Ciudad Bolívar.

\section{La imposibilidad del vínculo: utopía y distopía en el rap}

Aunada a la representación de la ciudad como gueto está la representación de la socialidad, entendida como la forma en que se explicitan las relaciones sociales. Aquí se evidencia una representación del sujeto urbano y de la manera en la que se construye con y para el otro. Los personajes del rap son solitarios, desencantados, ausentes de vínculos. Todos hacen consciente la necesidad de fortalecerse y de construir un destino que ve el sueño comunitario como algo inalcanzable.

Es que uno viene sólo al mundo, igual se va uno como el universo, como el cielo, y el momento que pasó como el sol irrepetible, única unidad divisible para los demás, mas si le pones uno, uno es el comienzo y pase, es mi dios soy rap y yo uno como el gobierno y la corrupción (Juan Habitual, Versos con números, 2007).

No existe oportunidad para construir una utopía colectiva, por el contrario, se propone el

5 Tal como es representado por el autor en Las reglas del método sociológico. 
egoísmo como la única forma de palear la ciudad de la sospecha. Hago énfasis en palear porque pensar la victoria es imposible al interior de este contexto discursivo, en donde no hay una orientación hacia ningún horizonte colectivo de carácter utópico: "Aunque la vida no sea lo que se esperó, cada quien busca a su medida una solución, detrás de la tormenta se esconde el sol no habrá perdedor, no hay ganador" (Diana Avella, Ciudad Fría, 2010).

De esto se colige que los amigos y los amores son impensables en las líricas del rap; en ellas impera la traición que tarde o temprano hará su arribo. "Malos muchachos, cuidado, las calles queman. Malos muchachos, muy pocos amigos afuera [...] Número uno: en los negocios no involucres faldas; número dos: si es de un amigo, con tu vida pagas" (Juan Habitual, Malos muchachos, 2007).

A pesar de que los raperos son representados como guerreros, en la calle, donde están sus pares, el honor no tiene ningún valor: "La palabra vale en el tiempo de saldar cuentas si hay plata, lujos y joyas mujeres contentas" (Flaco Flow \& Melanina, Vueltas son vueltas, 2008). Ante este panorama tan egoísta y anómico, resulta muy interesante pensar los colectivos de artistas que, al parecer, son nota común de la actividad artística rapera de las localidades. Esta fractura entre discurso y práctica no puede ser abordada acá, pues desbordan los alcances de este artículo; no obstante, podría ser un tema interesante para futuros trabajos.

La oda constante a la desconfianza se relaciona con el hecho de que buena parte de los personajes del rap obedecen a la figura del gánster y, en muchos casos, son mezcla de M.C. y pandilleros (Fondo blanco, Roberto Bruto, 2009). Así, la lógica de la pandilla se extiende a la vida social, haciendo que la posibilidad de construcción colectiva no exista, a diferencia de los procesos reales de los raperos, en donde se evidencian procesos de organización social y de generación de vínculos para la producción y difusión musical.

Confianza en dios, ya nadie confía en vos; faltones, en este negocio como arroz, no hay tiempo para llorar, sólo tienes que enfrentar, morir o matar o ser la presa o cazar, depende de cada cual estando mal, que el destino de cada quien es como un juego de azar. (Flaco Flow \& Melanina, Vueltas son vueltas, 2007).

El rapero es un sujeto solitario y la experiencia le hace descubrir la traición muy cerca:

Los proyectos colombianos raíces negras y he llorado es por que tú y las vivencias me han enseñado que los que siempre he creído que están de mi lado se les olvidó, monedas de cuero resultaron los hijos del sol (Fondo Blanco, Tosco, 2009).

En consonancia, La Etnnia propone en su lírica: "Aquí en el día, día nadie en nadie se confía, tú en nosotros, en nosotros nadie se fía. (La ciudad de la sospecha, 2008).

Discurso y práctica toman orientaciones distintas: la lírica es distópica, porque en la canción se renuncia al futuro, se destruye la posibilidad de la utopía; aunque en la cotidianeidad el parche construya redes sociales y proponga formas de organización para la gestión cultural, como es el caso de los colectivos: Crack Family, Contrapeso, Revolución Artística Popular, Mesa de Raperos del Amparo, entre otros. Reiteramos la visión negativa del rapero, en relación al vínculo social, con el siguiente fragmento de la canción nocturno de la agrupación La Etnnia:

Es hora de tener cuidado, donde está parchado hay más de uno entonado, mejor andar sólo que mal acompañado, no se fía él de nadie y así anda relajado, con estimulante que fluye por su sangre camina solitario haciendo su balance, y la nicotina irrita su retina, no le falta la línea de blancalina, que agita, cruza el carro y luego le pita, no importa, no les debe nada pero evita (Nocturno. 2008).

Diana Avella, en su canción aduladores, parece asentir la propuesta de sus colegas de La Etnnia. Veamos:

Cuál es la intención: ganar a toda costa sin importar perdedor, un mundo de competición, creado de avaricia, perfecto para quienes aman la hipocresía. La verdad sea dicha y sin temor afirman: hay que cuidarse más de los que ofrecen amistad (Adulaciones, 2010). 
El hermano, el vecino, el allegado, podría ser el enemigo; como Fredo y Michael, los personajes del padrino, quienes son invocados por JHT para representar la imposibilidad del vínculo fraterno. Un elemento constitutivo de la discursividad del colombiano es la propensión al atajo y a la trampa. Seguramente, estos elementos se manifiestan en diferentes contextos culturales, pero en el nuestro han devenido en la naturalización de algunas categorías comprendidas por todos y reproducidas en la imaginería popular. Desde el lenguaje se reproduce una visión que privilegia la astucia más allá de la legalidad y los valores ciudadanos. "El onceavo mandamiento": "la ley de la papaya" (a papaya puesta papaya partida), se convierte en un mandato ético que sustenta la traición y pone los medios por encima de los fines. El rap retoma esta premisa del sentido común en la siguiente canción: "El hombre se mueve y su filosofía es tome para que lleve. Escuche bien, tome para que lleve, en la búsqueda del pan. Al precio del que sea y sus malas intenciones es muy difícil que se vean" (La Etnnia, El allegado, 2010).

Lo mismo encontramos en Diana Avella, otra vez en su canción adulaciones: "Un mundo vacío, mata la sangre, llena la codicia, comercio de carne, son seres humanos vendidos y más. No hay que pensar, tener y comprar, vestir, reflejar, oír y callar, ver y engañar, a donde camina esta humanidad" (2010).

El bien y el mal son dos categorías que aparecen frecuentemente en el rap y están siempre puestas en duda. Estar "parchado" en la marginalidad, como dice La Etnnia, es no saber dónde está el bien y en dónde está el mal. Esta crisis moral representa el carácter distópico y anómico de los letristas del rap, el cual no aparece desligado de una situación macrosocial que se conecta con la misma construcción de lo juvenil, que debe ser vista hoy desde una perspectiva crítica y cuestionadora. Autores como Auge, Reguillo, Perea, Maffesoli, entre otros, han abordado esta crisis, conectando la increíble condición raquítica de nuestras sociedades, simbólicamente hablando, con las dinámicas juveniles contemporáneas.
Veamos lo que señala Martín Barbero en su texto Desorden cultural y palimpsestos de identidad:

¿Con qué queremos que sueñe una juventud alimentada cotidianamente - no sólo y no tanto en la televisión sino en la casa, la calle, en el trabajo- con el afán de lucro fácil, con el dinero y el confort como valores supremos, con la confusión del inteligente con el listo, es decir, con el que sabe engañar y trepar rápido, con la corrupción como estrategia de ascenso tanto en la clase política como empresarial? ¿Qué entusiasmo por los proyectos colectivos le están transmitiendo las derechas y las izquierdas? ¿Qué imágenes de respeto a las normas le enseñan hoy unos ciudadanos mayoritariamente tramposos, ventajistas, aprovechados? ¿Qué experiencias de solidaridad o generosidad les ofrece hoy a los jóvenes una sociedad desconfiada, recelosa, profundamente injusta y sin embargo estancada y conformista? (MartínBarbero, 2009, p. 23).

Los raperos están inmersos en unas condiciones estructurales y simbólicas que los determinan, dándole sentido a su denuncia y conectándola con la sensación de vacío que experimenta el sujeto contemporáneo (Taylor, 1994). En esa situación, no puede esperarse otra cosa que una variedad de relatos sobre la traición. Algunos de ellos terminan por naturalizar la mentira aunque otros la señalen.

Aunque la traición se reproduce como un elemento "natural de la vida social", ésta es vista como una falta a un código de honor que debería primar en las relaciones ente pares.

Canta, canta, canta el capo, paso de patrón a ser un buen sapo, paso de traficante a ser un informante, que pasó con tu criterio de maleante. Es el día a día de mi Colombia fría y el patrón canta en la Fiscalía (La Etnnia, El Patrón, 2008).

Resulta interesante que en esta canción no operen las vinculantes cívico ciudadanas, sino las reglas éticas de la mafia. En el texto se habla del criterio de maleante, aludiendo implícitamente a un ethos en donde debería primar el honor más allá de la conveniencia personal. Parece contradictorio que después de muchas canciones sobre la traición se denuncie la falsedad, pero forma 
parte de la moralina del rap, y en general, de nuestro contexto, en donde se heroiza al delincuente pero se le castiga con todo el peso de la justicia divina que siempre termina igualando los tantos.

Aquí los personajes transgresores son vestidos con el mismo traje heroico de los personajes de las narconovelas y los narcocorridos; pero al final, como en una fábula moralizante, el bien triunfa sobre el mal, a pesar de la ausencia de normas cotidianas.

Un oficial atravesó ahora a la fuerza, le pidieron documentos, recordó sus momentos cruentos, rayados de actos violentos, ya en el piso, lo trataron como rata, le dieron la de golpes, le dieron la de pata. Le decían: usted no es lo que dice ser, y él comprendía que acababa de perder (La Etnnia, Ilegal, 2008).

"Viviendo a toda" parece ser la consigna, sobreviviendo a la ciudad de la sospecha, trampeando para seguir vivo, corriendo en la ficción agitada de un mundo hostil, pero siempre seguro que el castigo está cerca. Es una visión desencantada y marginal pero a la vez religiosa de la vida misma.

Anda a la deriva en la vida porque la traición a él lo incentiva. Parte del castigo de tu fiel amigo. Cuidado la llave puede estar contigo. Así es que te lo digo. Así te lo predigo. Parte del castigo de tu fiel amigo. Cuidado, la llave puede estar contigo (La Etnnia, El allegado, 2008).

\section{Los enemigos: la sociedad,} el Estado, la Policía, los medios de comunicación y la fábrica

Uno de los personajes centrales dentro de la discursividad del rap es la sociedad, la cual aparece representada, al igual que el gueto, como una categoría imaginada, compuesta por los otros, por los que miran de soslayo al gueto. La sociedad es la némesis del gueto, está al otro lado del ring, señalando, corrompiendo, asesinando y excluyendo:
¿Por qué será que la sociedad está tan materialista? Si tú no tienes nada, no vales nada, si no tienes dinero tienes que aguantar la necesidad; por qué será que es tan fácil hablar de guerra y tan difícil hablar de paz, por qué será que son muchos los que tienen poco y son pocos los que tienen más (Flaco Flow \& Melanina, Atención).

El tono pasional ilustra muy bien la sensación que produce la palabra: sociedad, al interior de estos discursos; sensación que claramente nos ayuda a develar las representaciones desde las cuales estos sujetos entienden el mundo social y su lugar en él.

Bauman plantea que la comunidad (2008) es una palabra que produce una sensación cálida, mientras la sociedad parece ser el depositario de todas las penurias vitales. La sociedad, cercana a la representación de la ciudad monstruo de mil cabezas, es una máquina difícil de transformar. En el rap se renuncia - por lo menos discursivamente- a cualquier utopía social. La denuncia y la anomia no devienen en propuesta, y el corolario que se colige con esta tragedia urbana es que la salida, sin duda, es la atomización y el ensimismamiento del sujeto.

Por otro lado, la memoria supone una comunidad de emociones, pero en Colombia pareciera no existir sino el sujeto fragmentado, aislado y sin valores cívicos internalizados. En el caso de los jóvenes, señala Pérez Tornero que existe una tendencia a pensar lo juvenil desde el aislamiento, lo que constituye en sí mismo una trampa para avanzar en la formación de actores sociales:

El joven será el héroe retórico y falso de nuestro universo cultural mientras se someta voluntariamente al aislamiento autocomplaciente que le propone el sistema. Este aislamiento hace de él un ávido consumidor y un inapetente sujeto que ignora, por sistema, al otro (2009).

Esta observación crítica de Pérez parece sernos de mucha utilidad para enfrentarnos a la manera en la que los M.C. se representan a sí mismos a lo largo de los textos del rap. Es necesario aclarar que el interés no es desvirtuar la 
intención del rap, pero tampoco sobre dimensionar la denuncia política de las culturas juveniles, sin pasarlas por el filtro saludable de la crítica. Quizás JHT, al interior de nuestra muestra, es quien más hace propuestas en sus canciones y permite que la esperanza asome en la trágica poética del rap.

Hemos dejado que la cizaña nos ponga en contra de una tierra que para nada nos daña, fue la ignorancia, no la lagaña, la que nuestra vista empaña y no nos permite ver que puede haber un mejor mañana (JHT, Colombia).

Al menos aquí asoma la esperanza de trascender el tono trágico del género. De otro parte, en el rap se proponen unas apuestas por entender la nación. Se habla de una Colombia desde la perspectiva del M.C., resaltando algunos elementos que configuran las representaciones que los raperos tienen del país. El tema Colombia, de JHT, sintetiza algunos de estos rasgos que se resaltan al interior de las líricas del género. Transcribimos los apartes más significativos de la canción:

Colombia, báñame de historia y si nuestras cabezas sufren demencia que sólo tu permanezcas en nuestras memorias (Nótese el tono casi religioso, como de plegaria). Colombia, Colombia y si de mi memoria algún día te alejas, no habrá problema, mi corazón es el que te recuerda [...] En medio de las montañas, en lo profundo de tus entrañas, tu vientre parió tus hijos y los ha endulzado con caña, crecimos con muchas mañas, entre distintas calañas, con un destino que se ensaña en exiliar tus hijos hacia España [...] Colombia es la riqueza que tu no ves, Colombia no es la pobreza que tu quieres ver, por que en Colombia no hay pobreza, en Colombia se ignora que hay riqueza, Colombia es aquella pepa roja que todos quieren beber (JHT, Colombia).

Algo que es muy importante resaltar es que esta canción es quizás la única en donde el texto se permite hablar de los contextos rurales. Como hemos repetido, el rap —en pleno auge de la renovación de la música folk, y en particular para nosotros, de la música costeña-, es una música citadina. En otra canción, el tono espi- ritual de la canción Colombia, en la que ésta se personifica como madre, se convierte de nuevo en una denuncia que, dicho sea de paso, resulta muy acertada:

Mi país, el más feliz según lo dictan las encuestas, en donde la música sólo habla de tragos y borracheras, donde el hombre promedio es de color acerado, trabajos son campos disimulados de contrabando y humanos; amo Colombia, la de los verdes paisajes, chocolate, changua y mujeres sensuales, pero no miento cuando digo me cago en el mundo y que el himno nacional no es mi motivo de orgullo. Gobernantes latinos son puro entretenimiento, es el chavo del ocho sin don Ramón en el elenco (JHT, Veneno, 2009).

La desesperanza frente a lo político aparece retratada con el tono sardónico y agudo del M.C. En esta puesta en escena de la nación se resalta la pasión propia del nacionalismo (más que en mi memoria mi corazón es el que te recuerda) matizada por la crítica de los procesos de reproducción cultural y al desarraigo de los emigrantes, por falta de oportunidades económicas. Aquí se sueña a Colombia en tonalidad de amor - odio. Se pone en juego la anomia, desesperanza y descreimiento frente al Estado; aquí Colombia es dolor, pero también es la inconsciencia de sus habitantes, como propone la canción, en cuanto representa la ausencia de identidad cultural y de autoestima del colombiano. Esto forma parte de las representaciones de identidad de los mismos M.C., puesto que ellos se auto afirman en negación a los valores tradicionales y a las prácticas y discursos que, según ellos, construyen al ciudadano promedio.

José Gutiérrez, en su texto De la pseudoaristocrácia a la autenticidad (1966), plantea cómo, en el uso del lenguaje, reproducimos una visión vergonzosa de lo que somos, y reificamos nuestra subalternidad y sumisión. El autor señala:

Me da pena pero [...] y luego soltamos la verdad [...] Así, a cada momento, reproducimos el viejo drama de América: el del humilde y bondadoso indígena que llegado el caso y como consecuencia de su falta de astucia, finca la verdad por encima de la arrogancia mentirosa del déspota, 
aún a riesgo de ser condenado al castigo de las minas o las encomiendas (p. 39).

El rap oscila entre la reproducción de esa sumisión, al pensar las juventudes urbano populares como condenadas a la marginalidad, y la crítica a esa posición sumisa, al poner, en voz de JHT, un llamado a la toma de consciencia del orgullo patrio. El rapero de las canciones no es sumiso, recordemos que es un guerrero, pero tampoco es propositivo, ni la esperanza le da para ser visionario ni revolucionario.

De la misma forma que el rap propone una manera de entender la ciudad y la nación, también hace alusión a las instituciones del Estado. Dentro de ellas, en particular, se habla de la Policía como aparato represor que reproduce una violencia estructural. El policía y el político son personajes recurrentes en las letras de las canciones que nos ocupan.

Me empezaron a pegar patadas en el culo. Me trataron como si fuera su trapo sucio del tercer piso a la puerta de la calle. Me llevaron con garrote los muy salvajes. Ningún ciudadano se dignó a ayudarme, sólo se limitaron a burlarse. En el tanque la cosa no mejoró, hacinado juntamente me encontraba yo. Conclusión: 24 horas de calabozo por hacer ni mierda, que grandioso (JHT, El Odio, 2009).

Más adelante, el M.C. complementa:

Una tarde mi parcero Kávelo iba con una nena en plena avenida y tropezaron, que mal, con mera garbimba; esto es un atraco ñero deme lo que tenga, ya Kávelo le pasó su celular panela. Kávelo le contó al teniente el atraco que esa misma tarde él sufrió, y sabe qué nos dice nuestro rey el paladín de la justicia y la de ley: tienen que andar armados para defenderse y también para lucirse frente a sus mujeres (JHT, El odio, 2009).

La degradación ética de la Policía, ciertamente fundamentada en la experiencia empírica, aparece personificada en el consejo que el teniente da a Kavelo (otro rapero bogotano) en el Odio. La masculinidad, asociada al ejercicio de la violencia, la ostentación traqueta del arma, es la en- señanza de la ley a los jóvenes M.C. De nuevo, JHT propone una escena crítica frente a los valores tradicionales y la violencia cultural que él identifica como flagelo nacional. Así mismo, en la canción La esquina, el mismo cantante presenta la calle como escenario de manifestación de lo político, como expresión de la inequidad, la opresión y la insuficiencia del Estado. La voz rapera percibe la falsa armonía de la seguridad democrática hecha una guerra sin fin en el asfalto: "Señor presidente, qué seguridad, su policía me golpea con alegre maldad, quiso sacar del campo el fusil, pero trajo al asfalto la guerra sin fin, es la esquina la que guarda nuestra política" (JHT, La esquina, 2009).

Las alusiones a las instituciones del Estado pasan también por la mención a la imposibilidad de ejercer el derecho a la salud y la educación, como parte de una política social insuficiente. Flaco Flow y Melanina, afro-colombianos desplazados, habitantes de Ciudad Bolívar y JHT, otro habitante del gueto, ven desde abajo el precario sistema de educación y salud:

Universidad soñó al graduarse, pero luego despierta y piensa en la tierra; la educación superior no es para pobres, cualquiera se presenta, por supuesto, a la u del Estado, un cupo entre 300 y no fue el beneficiado, luego en busca trabajos sin certificados (JHT, La esquina, 2009).

Necesitas atención y te mueres en el andén, porque la operación no la paga el Sisben, oh, qué bien, tan bacano tener Sisben (Flaco Flow \& Melanina, Atención, 2008).

Probablemente existan algunos "moldes" transnacionales que prefiguran la discursividad del rap; sin embargo, en el caso de Colombia, éstos adquieren formas particulares al resaltar la desigualdad estructural que más que ser una ficción musical, es una verdad de a puño. Así, nos vemos obligados a pensar cómo opera en este caso el poder perlocutivo (Austin) del lenguaje. ¿Qué incidencia tiene que un puñado de cantantes de un género subalterno como el rap esté cantando a la insuficiencia del Estado? ¿Se produce algún proceso de movilización u otra ac- 
ción política práctica? Estas preguntas rebasan la intención del presente estudio. No obstante, podemos apuntar que son muy pocos los procesos de reivindicación sociopolítica desarrollados desde los grupos juveniles raperos, aunque por lo menos ellos siguen oficiando el noble oficio de la sospecha. Quizás, si pasaran de la denuncia a la acción habría posibilidad de ver de manera más clara el poder instituyente de su música, sin perder de vista que ésta no es, ni tiene porque evaluarse en sus resultados políticos.

Esta discusión nos permite traer a colación lo planteado por Bourdieu sobre los artistas en su texto El sentido social del gusto, donde explica el lugar de los mismos artistas en el espacio social:

Excluidos del poder político y económico, arrojados por la mayoría en la miseria dorada de la vida de bohemio, los artistas encuentran en la contestación simbólica del orden burgués que los excluye (al menos tanto como ellos lo excluyen) una manera de revertir simbólicamente su relación hacia su situación objetiva, es decir, hacia la relación que se establece objetivamente entre quienes detentan el poder y los artistas o los intelectuales coaccionados a pagar la autonomía que les es concedida por su desplazamiento hacia prácticas destinadas a permanecer simbólicas, sean simbólicamente revolucionarias o revolucionariamente simbólicas (2010, p. 70).

Junto con la sociedad, la nación, el Estado y la Policía, aparecen los medios de comunicación como un nuevo enemigo, los cuales, para los M.C., homogenizan el pensamiento de los sujetos. Raperos como JHT han ubicado un nuevo némesis del hip hop: el reggaeton, como símbolo del placer irreflexivo, tan adecuado a la lógica pop de los medios de comunicación.

Sírveme una copa más, borracho hasta el amanecer, la venenosa música que venden para tu ser, con su poder te hacen creer un chico cool, a la moda, y sólo eres uno más en una multitud simplona, el modelo Pepsi Cola de pancartas y revistas, tu modelo a seguir para lanzar a la vista o el regaetonto con videos de mansiones y lujos, en sus piscinas alquiladas y alquilados culos (JHT, Es veneno, 2009).
Esta crítica resulta muy aguda en cuanto va en contravía de los discursos que constituyen la juventud desde los medios de comunicación. La propaganda de la empresa de cerveza Bavaria promulga: "Celebra colombiano que es como mejor te ves", slogan que acompaña la foto de una mujer joven, hermosa y semidesnuda. Ese modelo del chico cool, dueño del placer, es atacado por la pluma mordaz del M.C., que evidencia en el mismo placer una atadura fundamental. Hay que decir que en medio de un panorama musical tan raquítico, resulta interesante ver otras posiciones que debatan la construcción social de la juventud. No obstante, y como es apenas predecible, los raperos se debaten entre la crítica a lo masivo y la intención de masificar su música. Esto se hizo evidente cuando en una entrevista a la joven cantante Electra, en la localidad de Kennedy, se refirió a JHT como un vendido al sistema, por haber prensado varios discos y haber adulzado su lírica. Yo me sorprendí, dada mi alta estima del cantante, pero luego comprendí que en la lucha por el underground el enemigo es el que está más cerca a la posibilidad de la popularidad.

Otra de los lugares sociales evidentes en las líricas del rap es la fábrica. En la canción Pablo Gueto de JHT, inspirada en la canción Pablo Pueblo de Rubén Blades, se relata el desempleado que pasa por la humillación de pedir trabajo. En una escena casi kafkiana, Pablo Gueto es auscultado por las psicólogas de selección de personal:

Presenta la famosa prueba del polígrafo, escarban en su alma, graban todo lo dicho, tiene buenas intenciones, quiere un fucking trabajo, tener seguro médico y comer como humano, lo manosean cual gusano, de su intimidad abusan, son los tiempos de Pablo y su lucha injusta, inmunda (JHT, Pablo Gueto, 2009).

La imposibilidad de conseguir trabajo hace que JHT, el narrador, coliga el destino de Pablo:

Por muy bien que le vaya el seguirá siendo esclavo, apto pa' malos tratos y para empleos baratos, un sueldo mínimo no alcanza para estudiar ni mirar alto. Él desearía estudiar, la inteligencia se va con códigos impuestos en la casa presiden- 
cial ¿Cómo paga pasajes? ¿Cómo paga matriculas? ¿Cómo puede aspirar a la vida que imagina? Pablo pueblo, no hay empleo, mas bien desempleo, hijo del grito y la calle (JHT, Pablo Gueto, 2009).

La inteligencia discursiva de los raperos, la que crea historias y metáforas, va contando la historia de un sector social específico, enfocan- do su esfuerzo en algunos fenómenos puntuales, rumiando algunos lugares comunes, espectacularizando la calle, asumiendo la imposibilidad de la utopía, denunciando la violencia estructural de nuestro sistema, poniendo a la luz la ideologización, a veces oculta, de las culturas urbanas juveniles.

\section{Referencias}

Abric, J. C. (2001). Prácticas sociales y representaciones. México D.F.: Coyoacán.

Alape, A. (2003). Ciudad Bolivar, la hoguera de las ilusiones. Bogotá: Planeta.

Amaya, A., \& Marín, M. (octubre, 2000). Nacidos para la batalla. Nómadas, 13, 64-73.

Bauman, Z. (2003). Comunidad. Buscando seguridad en un mundo hostil. Barcelona: Siglo XXI.

Bourdieu, P. (1995). Respuestas por una antropología reflexiva. México D. F.: Grijalbo.

Madrid: Akal.

(2008). ¿Qué significa hablar?

. (2010). El sentido social del gusto.

Buenos Aires: Siglo XXI.

Castiblanco, G. (2008). Identidades juveniles, música y producción cultural. Etnografía de agrupaciones rave y hip hop rap en Bogotá. Bogotá: Colegio Mayor de Cundinamarca.

Garcés, Á. (2009). Etnografías vitales: músicas e identidades juveniles. Hip hop en Medellín. Folios, 21-22, 125-140.
García Naranjo, J. P. (2006). Las rutas del giro y el estilo. La bistoria del breakdance en Bogotá. Bogotá: Universidad del Rosario.

Jodelet, D. (1998). La representación social: fenómenos, concepto y teoría. En S. Moscovici (Comp.). Psicología Social II. Pensamiento y vida social. Psicología social y problemas sociales (pp. 469-494). Barcelona: Paidós.

Martín-Barbero, J. (enero-junio, 1999). Las transformaciones del mapa: identidades, industrias y culturas. Ambitos, 2, 7-21.

Perea, C. M. (2001). Somos expresión, no subversión. Palimsestus 1.

Reguillo, R. (2006). Emergencia de las culturas juveniles. Estrategias del descanso. Bogotá: Norma.

Ricoeur, P. (2000). Del texto a la acción. Buenos Aires: Fondo de Cultura Económica.

Rodríguez Leuro, J. (1998). Jóvenes, cultura y ciudad. Bogotá: Observatorio de cultura ciudadana.

Taylor, C. (1994). La ética de la autenticidad. Barcelona: Paidós.

Toner, A. (1998). Hip Hop. Madrid: Celeste. 